\title{
Characterizing trophic ecology of generalist consumers: a case study of the invasive lionfish in The Bahamas
}

\author{
Craig A. Layman ${ }^{1, *}$, Jacob E. Allgeier ${ }^{2}$ \\ ${ }^{1}$ Marine Sciences Program, Florida International University, 3000 N.E. 151st St., North Miami, Florida 33181, USA \\ ${ }^{2}$ Odum School of Ecology, University of Georgia, Athens, Georgia 30602, USA
}

\begin{abstract}
Population sizes of generalist consumers are increasing in many ecosystems because of various human activities, and it is critical to understand the trophic role of these generalist species if we are to predict how they may affect food web structure and ecosystem function. Lionfish Pterois volitans/miles have spread throughout the Western Atlantic and Gulf of Mexico and they may have significant effects on native faunal communities. We characterized the trophic ecology of lionfish in back reef habitats on Abaco Island, Bahamas, drawing on recently developed analytical tools that employ both direct diet information and stable isotope data. Although $\delta^{15} \mathrm{~N}$ and $\delta^{13} \mathrm{C}$ bi-plot data appeared to suggest substantial niche overlap with native gray snapper and schoolmaster snapper, Bayesian analytical tools suggested differences in core isotopic niches among the species. This was consistent with direct diet information, as lionfish fed almost exclusively on small prey fishes and snapper fed more commonly on crustaceans. When combining empirical isotope and diet data in a simulation model, individual lionfish appear to be more specialized in their diets than schoolmaster snapper. We suggest that this pattern may be driven by high site-fidelity of lionfish, in conjunction with distinct prey assemblages at the patch scale. Lionfish are widely considered to be generalist predators, and our data reveal aspects of this trophic generality that must be considered as the role of lionfish in their invaded habitats continues to be examined.
\end{abstract}

KEY WORDS: Food web - Individual specialization - Invasive species - Optimal foraging · Predator-prey interaction $\cdot$ Pterois volitans $\cdot$ Pterois miles

\section{INTRODUCTION}

An emerging global trend is the extinction or extirpation of more specialized species, with a concomitant spread of generalist ones, with the latter known as the 'winner' species (McKinney \& Lockwood 1999, Clavel et al. 2011). This trend, referred to as biotic homogenization, can have drastic implications for community structure and ecosystem function (Olden et al. 2004). Several anthropogenic activities drive biotic homogenization, including the spread of invasive species (Mack et al. 2000, Olden et al. 2004, Qian \& Ricklefs 2006). Marine ecosys- tems have not been spared from the effects of invasions (Carlton 1989, Ruiz et al. 1999). Although, historically, other impacts (e.g. habitat destruction, direct over-exploitation) have been more important in affecting ecosystem function in marine systems (Jackson et al. 2001, Lotze et al. 2006), effects stemming from species invasions are increasing rapidly (Carlton 1989, Ruiz et al. 1999, Byrnes et al. 2007).

Causes of, and implications following, biotic homogenization relate to the generalist nature of the 'winner' organisms. Invasive species often are generalists (Olden et al. 2004), e.g. in terms of diet or envi- 
ronmental tolerances (although there are many exceptions; Kolar \& Lodge 2001), which may facilitate their spread. Once established, the presence of a novel generalist consumer may have important implications for the invaded ecosystems. Food web structure is often altered following invasion, ultimately driving shifts in ecosystem function (Mack et al. 2000, Clavel et al. 2011). For example, the invasive European periwinkle snail Littorina littorea, a generalist herbivore, structures littoral communities along the northeast coast of North America, affecting the function of both soft-sediment and salt marsh systems (Bertness 1984). In this context, characterizing the fundamental nature of a species' 'generality' is crucial for understanding its role in food web structure and dynamics.

Recently, a renewed interest into characterization of generalist species has emerged (Araújo et al. 2011, Bolnick et al. 2011, Clavel et al. 2011, Loxdale et al. 2011). Much of this research focuses on individual specialization, i.e. when a generalist population is actually composed of specialized individuals whose niches are small subsets of the population niche (Bolnick et al. 2003). Individual specialization is a widespread phenomenon in natural populations and might fundamentally alter our traditional view of trophic ecology and food web dynamics (Araújo et al. 2011, Bolnick et al. 2011). This context may provide important new insight into the feeding ecology of invasive species and their potential impacts on food web structure.

The invasive lionfish Pterois volitans/miles (hereinafter called lionfish) has spread throughout the Western Atlantic and Gulf of Mexico (Whitfield et al. 2002, Schofield 2009, Mumby et al. 2011). Lionfish may have significant effects on native communities, and the invasion has been identified as one of the top 15 emerging environmental issues at a global scale (Sutherland et al. 2010). One of the reasons for lionfish's apparent success, and associated detrimental impacts, is their voracious predatory nature, and ability to exploit a wide range of prey (Morris \& Akins 2009, Barbour et al. 2010, Côté \& Maljkovic 2010, Jud et al. 2011, Muñoz et al. 2011). In the most extensive diet study to date, Morris \& Akins (2009) identified 41 teleost taxa, as well as numerous crustacean species, in lionfish stomachs. The large number of individuals sampled, as well as the diversity of habitat types included (ranging from shallow mangroves to artificial habitat to coral reefs), render the study a comprehensive assessment of diet generality at a regional scale (Morris \& Akins 2009). In the present study, we delve more specifically into local patterns of diet variation, and explore diet generality within a single back-reef (sensu Adams et al. 2006) ecosystem in The Bahamas.

In the last $5 \mathrm{yr}$, a series of quantitative tools have emerged to more fully characterize the ecological role of trophic generalist species (Araújo et al. 2011). Drawing on these recently developed analytical tools, we characterized the trophic ecology of lionfish in The Bight of Old Robinson, Abaco, Bahamas. We employed both direct diet information and stable isotope data, complementary data sets that together can provide for detailed insight into the overall trophic role of organisms (Layman \& Post 2008, Layman et al. 2011). Our primary questions were:

- What are the primary diet items of lionfish in a back reef habitat and, for comparative purposes, 2 native sympatric species (gray and schoolmaster snapper)?

- Based on traditional measures of population-level diet overlap, as well as recently developed Bayesian and frequentist statistics for stable isotope data, do lionfish and snapper fill similar trophic roles in this ecosystem?

- What is the relative degree of individual specialization within this lionfish population, and how does that compare to the native generalist snapper species? What factors may give rise to the observed patterns of specialization?

We intended the methodological approach and discussion topics raised herein to reveal new aspects of the lionfish invasion, but also to guide similar studies of generalist taxa in marine systems.

\section{MATERIALS AND METHODS}

\section{Study site and sampling}

The present study was conducted in The Bight of Old Robinson, Abaco, Bahamas. The Bight of Old Robinson is a semi-enclosed bay, with a mosaic of seagrass, sand, hard-bottom, rocky outcroppings, and patch reef habitats (Yeager et al. 2011). All structurally complex habitats in a $\sim 1.5 \mathrm{~km}^{2}$ area were surveyed opportunistically from May 2009 to March 2011. Lionfish were killed using spears during daytime hours. Collection locations included coral heads, ledges under rocky outcroppings, and mounds of dead coral rubble. Lionfish were captured at depths of 0.2 to $2.4 \mathrm{~m}$. Local fishers and recreational divers frequently removed lionfish in this area during the study period (largely due to public education efforts 
on the island); therefore, we do not report lionfish densities. During the collection period, schoolmaster snapper Lutjanus apodus and gray snapper L. griseus also were collected from the same sites as lionfish. These are among the most common species in back reef habitats of The Bahamas, and may feed on similar prey taxa as lionfish (Layman et al. 2007b, Valentine-Rose et al. 2007, Hammerschlag-Peyer \& Layman 2010).

\section{Stomach content analysis}

Stomach contents of the 3 focal predator species were identified to the lowest taxonomic level possible, and the volume of each prey item estimated with a graduated cylinder. Several prey were combined into higher-level taxonomic categories because of the difficulty of species-level identification of partially digested prey. Diet similarity between species was assessed using Schoener's diet overlap index (Schoener 1968):

$$
D=1-1 / 2 \Sigma\left|p_{i j}-p_{i k}\right|
$$

where $D$ is the index value, and $p_{i j}$ and $p_{i k}$ is the relative proportion of each food item $i$ for species $j$ and $k$, respectively. On this scale, 0 represents no overlap and 1 represents complete overlap between 2 compared species. Typically, values $>0.6$ are inferred to indicate significant dietary overlap (Schoener 1968).

\section{Stable isotopes}

For stable isotope analysis, ratios of ${ }^{15} \mathrm{~N}:{ }^{14} \mathrm{~N}$ and ${ }^{13} \mathrm{C}:{ }^{12} \mathrm{C}$ were employed. Stable isotope values are reported in the $\delta$ notation, where

$$
\delta^{13} \mathrm{C} \text { or } \delta^{15} \mathrm{~N}=\left[\left(R_{\text {sample }} / R_{\text {standard }}\right)-1\right] \times 1000,
$$

and $R$ is the ${ }^{13} \mathrm{C}:{ }^{12} \mathrm{C}$ or ${ }^{15} \mathrm{~N}:{ }^{14} \mathrm{~N}$ ratio. We focused on ratios of $\delta^{15} \mathrm{~N}$ and $\delta^{13} \mathrm{C}$ because each reveals a distinct aspect of a consumer's long-term trophic niche. $\delta^{15} \mathrm{~N}$ exhibits stepwise enrichment with trophic transfers, and can thus be used to estimate an organism's trophic position relative to that of others in a food web (DeNiro \& Epstein 1981, Post 2002). $\delta^{13} \mathrm{C}$ varies substantially among primary producers with different photosynthetic pathways (e.g. C3 vs. C4 plants), but changes little with trophic transfers, and can thus be used to infer sources of dietary carbon (Peterson \& Fry 1987, McCutchan et al. 2003). Stable isotopes provide useful insight into trophic ecology because they provide time- and space-integrated representa- tions of potential dietary pathways (Layman et al. 2011).

Stable isotope preparation of predator and prey tissues was based on Post et al. (2007) and the analysis was conducted at the Yale Earth Systems Center for Stable Isotopic Studies, New Haven, CT. For the focal predator species, $\sim 1 \mathrm{~cm}^{3}$ of muscle tissue, just posterior to the dorsal fin, was used. All identified prey taxa from stomach content analysis were collected from similar habitats, on multiple occasions, during the same sampling period. Each sample was dried at $60^{\circ} \mathrm{C}$ for a minimum of $48 \mathrm{~h}$, after which the dry weight was measured. For invertebrates, separate analyses were performed for $\delta^{13} \mathrm{C}$ and $\delta^{15} \mathrm{~N}$, with samples for $\delta^{13} \mathrm{C}$ being first acidified to remove inorganic carbon.

\section{Niche location and width}

We examined isotopic niche position following Turner et al. (2010). This approach expands on the convex hull metrics first described by Layman et al. (2007a), an index of the isotopic niche that is useful because it accounts for every individual's niche in the population sub-sample (for more discussion of the pros and cons of this approach, see Layman et al. 2011). Following Turner et al. (2010), we used nested linear models and residual permutation procedures to generate and compare measures of central tendency for each respective population. The isotopic niche location is considered to be different if the Euclidean distance between the 2 groups is significantly greater than zero. Script for running these statistics in $\mathrm{R}$ and additional detail can be found Turner et al. (2010).

Niche width was calculated using a Bayesian approach based on multivariate ellipse-based metrics (Jackson et al. 2011). This approach is appropriate to identify differences in niche widths of 'typical' members of a population (i.e. it may not encompass outlier individuals in isotopic space), and is especially useful when comparing populations with different sample sizes (Jackson et al. 2011). The analysis generates standard ellipse areas $\left(\mathrm{SEA}_{\mathrm{B}}\right)$, which are bivariate equivalents to standard deviations in univariate analysis. Following Jackson et al. (2011), SEA $A_{B}$ was graphically expressed using a corrected $\mathrm{SEA}_{B}$ value to minimize bias across the ranges of sample size for each population. $\mathrm{SEA}_{B}$ were calculated following methods from Jackson et al. (2011) and the R package SIAR (Parnell et al. 2010). 


\section{Individual specialization}

When used together, stable isotope and stomach content analysis are powerful tools to quantify the degree of individual specialization. To this end, we employed the model of Araújo et al. (2007) in which the variance in individual $\delta^{13} \mathrm{C}$ values in a population of consumers (in this case, schoolmaster snapper and lionfish), the $\delta^{13} \mathrm{C}$ values of resources, and direct dietary information are used to calculate indices of individual specialization (Bolnick et al. 2002). In this approach, the observed population diet (from the stomach content analysis) is used to generate a large number of simulated populations with varying degrees of individual specialization. Empirical prey isotope ratios and prey volumes (average volumes from stomach content analysis) are then used to calculate the isotopic variance for each simulated population. These simulations allowed us to establish a curve relating expected isotopic variances to specific degrees of individual specialization (e.g. Fig. 3). Finally, we used this relationship to convert empirical variance in schoolmaster and lionfish isotope values into an estimate of individual specialization in that particular population. The calculations were performed in the program VarIso (www2.fiu.edu/ $\sim$ marine/araujo/software.html) using 5700 simula- tions following Araújo et al. (2007). To avoid confusion, we term this an 'index of diet generality' so that populations with values closer to 1 consist of more generalist individuals, and populations with values closer to zero have a relatively high degree of individual-level specialization in diet. This index is equivalent to the 'IS' measure in Bolnick et al. (2002) and Araújo et al. (2011).

\section{Prey fish composition}

Because results suggested a high degree of individual specialization in lionfish (see section 'Individual specialization' under 'Results'), we completed a supplementary study in May 2011 to explore one potential mechanism that may affect lionfish diets in this study system. For these surveys, we chose the 9 sites where we had collected the most lionfish from 2009 to 2011. These sites included live coral heads, outcroppings covered by coral, sponges and algae (see Fig. 1 as an example), and rocky ledges (hereinafter, all referred to as 'patch habitats'). Depth of the patch habitats ranged from $\sim 0.6$ to $2.0 \mathrm{~m}$ at low tide. In a circle (radius: $1 \mathrm{~m}$, area: $3.14 \mathrm{~m}^{2}$ ) that included the patch habitat, we recorded the presence of all potential prey of lionfish, i.e. all fish $<\sim 8 \mathrm{~cm}$ in

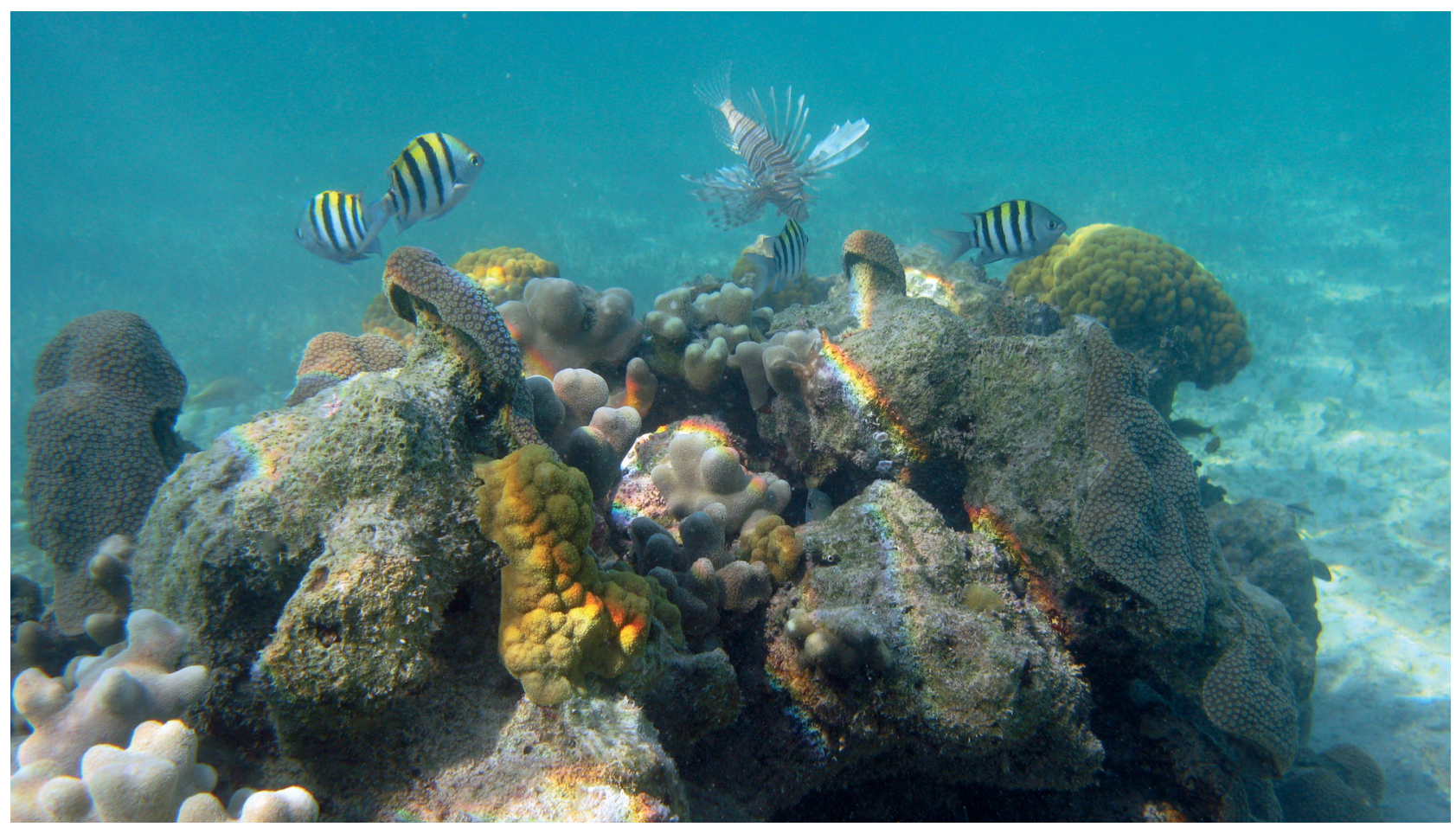

Fig. 1. Pterois volitans/miles. Example of one of the patch habitats surveyed in this study 
Table 1. Stomach content analysis of Pterois volitans/miles, Lutjanus griseus, and L. apodus

\begin{tabular}{|lccccc|}
\hline Species & $\begin{array}{c}\text { No. stomachs } \\
\text { examined }\end{array}$ & $\begin{array}{c}\text { No. stomachs } \\
\text { empty }\end{array}$ & $\begin{array}{c}\text { \% Stomachs } \\
\text { empty }\end{array}$ & $\begin{array}{c}\% \\
\text { Crustaceans }\end{array}$ & $\begin{array}{c}\% \\
\text { Fish }\end{array}$ \\
\hline Lionfish & 122 & 23 & 19 & 91 & 51 \\
Gray snapper & 166 & 123 & 74 & 85 & 15 \\
Schoolmaster snapper & 64 & 28 & 44 & & 59 \\
\hline
\end{tabular}

total length (TL). We visited these sites 6 times from May 8 to 29, repeating fish surveys each time. The number and exact location of lionfish also were recorded in each survey.

We used non-metric multidimensional scaling (NMDS) to examine if prey fish assemblages differed among patch habitats. NMDS graphically represents, in 2 dimensions, relationships between objects using the Bray-Curtis similarity index (Bray \& Curtis 1957). In ordination plots, as distance between points (representing fish composition for a single survey) increases, similarity of species composition between the 2 surveys decreases. Analysis of similarities (ANOSIM), a non-parametric analog to multivariate analysis of variance (MANOVA), was used to test for significant differences in patch species composition. NMDS and ANOSIM were conducted in Primer 5 (version 5.2.9, PRIMER-E).

\section{RESULTS}

\section{Stomach content analysis}

Stomach contents were examined for 122 lionfish (mean standard length [SL]: $143 \mathrm{~mm}$, range: 60 to $208 \mathrm{~mm}$ ), 166 gray snapper (mean SL: $201 \mathrm{~mm}$, range: 121 to $335 \mathrm{~mm}$ ), and 64 schoolmaster snapper (mean SL: $181 \mathrm{~mm}$, range: 127 to $235 \mathrm{~mm}$; Table 1). Lionfish had a lower proportion of empty stomachs $(19 \%)$ than the 2 snapper species (schoolmaster: $44 \%$, gray snapper: $74 \%$ ). Because of the high proportion of gray-snapper empty stomachs, no further analysis involving diet contents was conducted for this species. Lionfish preyed primarily on small fishes (Table 2), including beaugregory damselfish Stegastes leucostictus, slippery dick wrasses Halichoeres bivittatus, parrotfish Sparisoma spp., and grunts Haemulon spp. In contrast, schoolmaster snapper diets consisted largely of small crustaceans (85\%). Schoener's diet overlap index value was 0.13 , consistent with low similarity in the diets of lionfish and schoolmaster snapper.

\section{Stable isotopes}

Mean $\delta^{13} \mathrm{C}$ values $\pm \mathrm{SD}$ (lionfish: $-11.8 \pm 0.65 \%$, $\mathrm{n}$ $=35$; gray snapper: $-10.8 \pm 0.49 \%$, $\mathrm{n}=53$; schoolmaster: $-11.4 \pm 0.99 \%$, $\mathrm{n}=49$ ) differed among species (Kruskal-Wallis: $\mathrm{p}<0.001$ ), with all 3 pairwise species comparisons significant (Dunn test: all $p<0.05$ ). Mean $\delta^{15} \mathrm{~N}$ values \pm SD (lionfish: $9.1 \pm 0.38 \%$, gray snapper: $8.8 \pm 0.39 \%$, schoolmaster: $9.3 \pm 0.46 \%$ ) also differed among species (ANOVA: $F_{2,133}=16.8, \mathrm{p}$ $<0.001$ ), with schoolmaster and lionfish $\delta^{15} \mathrm{~N}$ significantly higher than gray snapper (Tukey test: both $\mathrm{p}<$ 0.001). Among individuals, schoolmaster snapper had the largest range of both $\delta^{15} \mathrm{~N}(2.3 \%)$ and $\delta^{13} \mathrm{C}$ $(4.3 \%$ ) (Fig. 2). Gray snapper and schoolmaster SL

Table 2. Pterois volitans/miles and Lutjanus apodus. Population diet composition (\% by volume) among those stomachs that contained prey (total number of lionfish prey $=129$, number of schoolmaster prey $=51$ )

\begin{tabular}{|c|c|c|}
\hline Prey species & $\begin{array}{l}\text { Contribut } \\
\text { Lionfish }\end{array}$ & $\begin{array}{l}\text { on to diet }(\%) \text { in } \\
\text { Schoolmaster }\end{array}$ \\
\hline Beaugregory & 24 & 0 \\
\hline Slippery dick wrasse & 24 & 0 \\
\hline Parrotfish & 14 & 5 \\
\hline Grunt & 12 & 0 \\
\hline Rosy blenny & 8 & 0 \\
\hline Bluehead wrasse & 2 & 0 \\
\hline Sergeant major & 2 & 0 \\
\hline Spanish hogfish & 2 & 0 \\
\hline Mithrax spp. crabs & 2 & 12 \\
\hline Snapping shrimp & 2 & 0 \\
\hline Portunid crab & 1 & 28 \\
\hline Doctorfish & 1 & 0 \\
\hline Mantis shrimp & 1 & 2 \\
\hline Pitho spp. crabs & 1 & 9 \\
\hline $\begin{array}{l}\text { Paneid and palaemonetid } \\
\text { shrimp }\end{array}$ & 1 & 14 \\
\hline Mud crab & 1 & 16 \\
\hline Yellowhead wrasse & $<1$ & 0 \\
\hline Seagrass & $<1$ & 0 \\
\hline Snail & $<1$ & 0 \\
\hline Coral banded shrimp & $<1$ & 0 \\
\hline Tricolored hermit crab & $<1$ & 0 \\
\hline Pachygrapsus spp. shore crabs & 0 & 13 \\
\hline
\end{tabular}



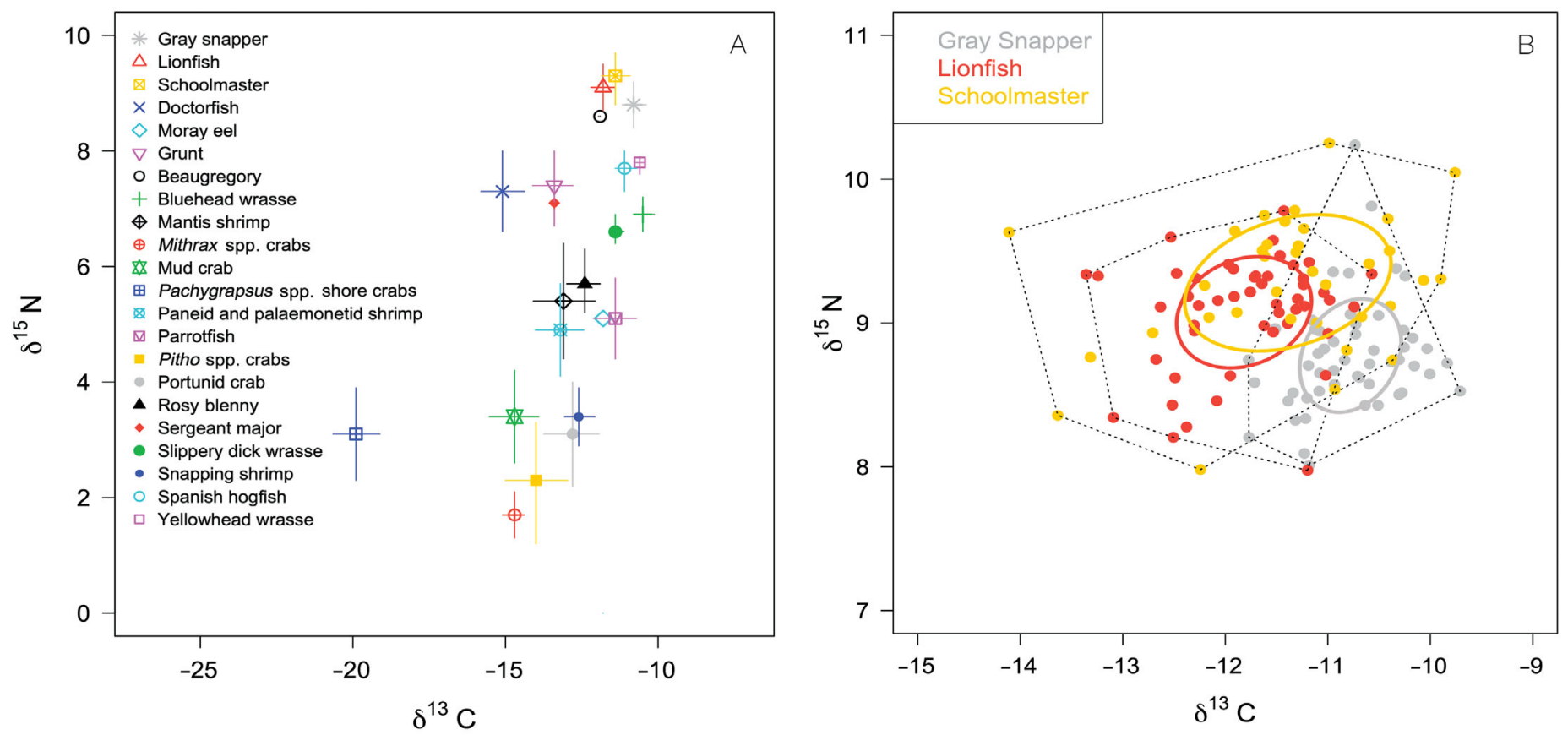

Fig. 2. Pterois volitans/miles, Lutjanus griseus, and L. apodus. (A) $\delta^{13} \mathrm{C}$ and $\delta^{15} \mathrm{~N}$ bi-plot of 3 focal predator species, as well as each prey item (1 to 25 individuals per taxa, mean \pm SD: $8 \pm 6.6$ ) identified in stomach content analysis. Values are mean \pm SD. Note the restricted range of prey $\delta^{13} \mathrm{C}$ values, especially among lionfish prey (from Table 2). (B) $\delta^{13} \mathrm{C}$ and $\delta^{15} \mathrm{~N}$ bi-plot with all lionfish, schoolmaster, and gray snapper individuals $(n=35,49$, and 52, respectively). Convex hulls of total niche width (following Layman et al. 2007a) are depicted using dashed lines. Standard ellipse area (SEA $A_{B}$ ) representation of isotopic niches, i.e. bivariate equivalents to SD in univariate analysis (following Jackson et al. 2011), are depicted with solid lines. Note different scales on the $x$ - and $y$-axes in both panels

was a significant predictor of $\delta^{15} \mathrm{~N}(y=7.6+0.0055 \times$ size, $\mathrm{p}<0.001, \mathrm{R}^{2}=0.29 ; y=7.4+0.01 \times$ size, $\mathrm{p}<$ $\left.0.001, R^{2}=0.29\right)$, but not $\delta^{13} C\left(R^{2} \leq 0.002, p \geq 0.6\right)$. SL was not related to $\delta^{15} \mathrm{~N}$ or $\delta^{13} \mathrm{C}$ for lionfish $\left(\mathrm{R}^{2} \leq 0.06\right.$, $\mathrm{p} \geq 0.18$ ).

Prey taxa $\delta^{15} \mathrm{~N}$ ranged from $1.7 \%$ (Mithrax spp.) to $8.6 \%$ (beaugregory damselfish) (Fig. 2A). Fishes tended to have higher $\delta^{15} \mathrm{~N}$ values than crustaceans. Prey $\delta^{13} \mathrm{C}$ values ranged from -10.5 (bluehead wrasse Thalassoma bifasciatum) to -19.9 (Pachygrapsus spp., supratidal shore crabs). The range of mean $\delta^{13} \mathrm{C}$ values was much smaller for lionfish prey items $(4.2 \%)$ than for schoolmaster prey $(8.5 \%)$. When applying an assumed trophic fractionation value of $\sim 1 \%$ (Post 2002), mean $\delta^{13} \mathrm{C}$ values of prey bounded the $\delta^{13} \mathrm{C}$ value of every predator individual, thereby meeting an important assumption of the individual specialization model detailed (Araújo et al. 2007).

\section{Niche location and width}

Differences in niche position were assessed based on Euclidean distance-based measures of central tendency (Turner et al. 2010). Using a permutation procedure with 1000 iterations, we found that the distance in mean centroid location between each pair of populations differed significantly from zero $(p<$ 0.01 ), suggesting each population had a different position in isotopic space. Although $98 \%$ of lionfish were found within the convex hull representation of the schoolmaster isotopic niche, the 2 populations' mean isotopic positions nonetheless differed significantly (Fig. 2B).

We also quantified niche widths for each population, by calculating $\mathrm{SEA}_{\mathrm{B}}$ using Bayesian inference (Jackson et al. 2011). The $\mathrm{SEA}_{B}$ values with 95\% Bayesian credible intervals (CI) were: lionfish-mean: 0.91, median: $0.90,95 \%$ CI: 0.67 to 1.18; gray snapper - mean: 0.71 , median: $0.70,95 \%$ CI: 0.53 to 0.90 ; and schoolmaster snapper-mean: 1.60, median: $1.57,95 \%$ CI: 1.10 to 2.16 . Comparing the relative size of ellipses among populations demonstrates that the niche width for schoolmaster snapper is significantly greater than both lionfish and gray snapper $(\mathrm{p}<0.001)$, whereas lionfish niche width did not differ from gray snapper $(p=0.9)$. 


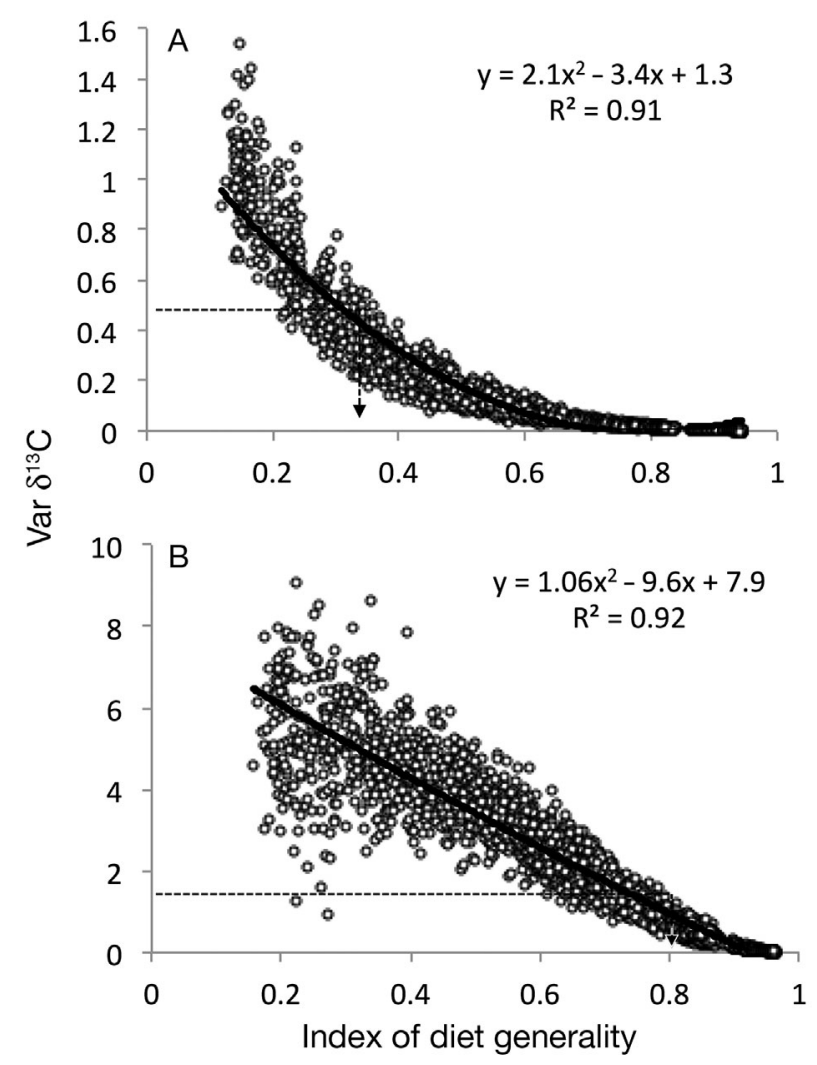

Fig. 3. Pterois volitans/miles and Lutjanus apodus. Regression of the variance in $\delta^{13} \mathrm{C}$ as a function of diet generality index for simulated populations of (A) lionfish and (B) schoolmaster snapper. Lower values along the $x$-axis represent increased degree of individual specialization within the generalist population (see 'Individual specialization' section for details). The solid curves indicate quadratic fitted regressions. Horizontal dashed lines are the actual empirical variance in $\delta^{13} \mathrm{C}$ for lionfish (0.42) and schoolmaster snapper (0.98). Arrows indicate the expected degree of individual-level diet generality based on the empirical variance in $\delta^{13} \mathrm{C}$ and the model regression relationship. Based on the empirical data of predator and prey isotope values, as well as the empirical dietary proportions of prey items, the model suggests a much higher degree of dietary specialization of individuals within the lionfish population $(0.34)$, relative to that of schoolmaster snapper (0.8); see Fig. 4 for additional context

\section{Individual specialization}

For the 2 species for which we had sufficient diet data (lionfish and schoolmaster snapper), we used the program VarIso to estimate the degree of individual specialization based on predator and prey isotope values and prey dietary proportions. From the predicted regression relationships (lionfish: $y=2.1 x^{2}-$ $3.4 x+1.3 ;$ schoolmaster: $y=1.06 x^{2}-9.6 x+7.9$; Fig. 3) and the empirically derived variance in $\delta^{13} \mathrm{C}$, lionfish had a relatively high degree of individual specialization. The index of diet generality was 0.34 , with values closer to zero representing a higher degree of individual specialization (see Fig. 4 for context based on other studies of individual specialization). In other words, the $\delta^{13} \mathrm{C}$ values for individual lionfish were highly variable relative to $\delta^{13} \mathrm{C}$ values of the prey items, suggesting that individual lionfish had to be feeding specifically on prey items with distinct $\delta^{13} \mathrm{C}$ values. In contrast, the estimated value of 0.8 for schoolmaster snapper suggested a relatively low degree of individual specialization. For schoolmaster, their common prey items were extremely variable in $\delta^{13} \mathrm{C}$. So even though at the population level, schoolmaster had a broader $\delta^{13} \mathrm{C}$ range than lionfish, the data suggest that individual schoolmaster were more generalist feeders. A much higher observed variance of $\delta^{13} \mathrm{C}$ in schoolmaster individu-

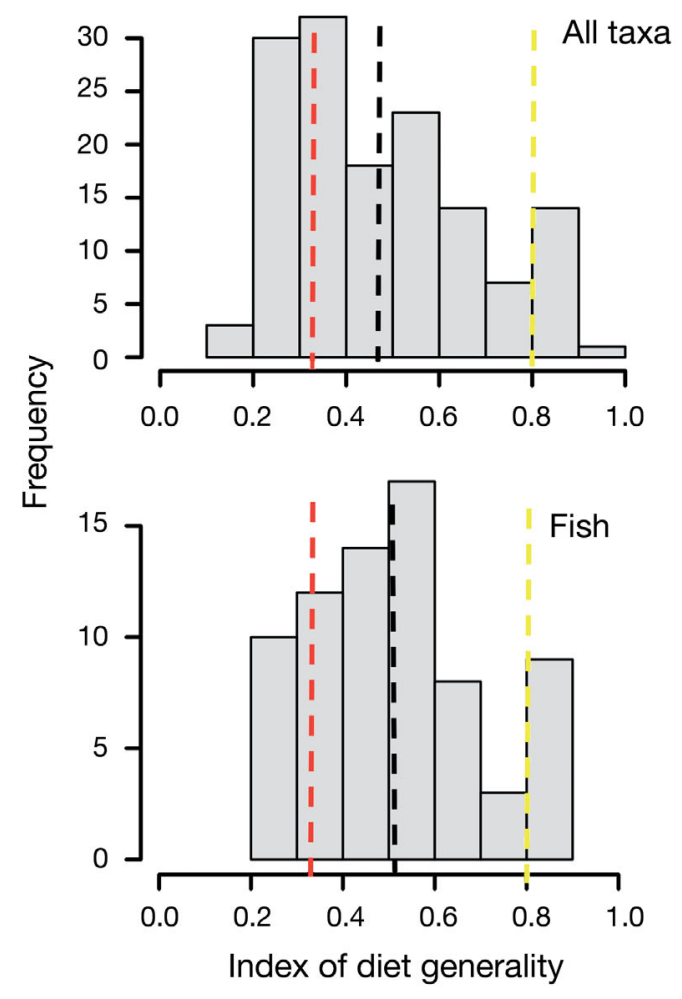

Fig. 4. Pterois volitans/miles and Lutjanus apodus. Relative degree of individual specialization for lionfish and schoolmaster snapper in the present study, placed in the context of a recent review of all published individual specialization values (A: all taxa, $\mathrm{n}=141$; $\mathrm{B}$ : fish, $\mathrm{n}=73$; Araújo et al. 2011). Populations with lower index values have a higher degree of individual specialization within the population (e.g. lionfish: red line). Populations that consist of more generalist individuals have higher index values (e.g. schoolmaster snapper: yellow line). The black line is the mean value of all studies within that category. Note different scales on the $y$-axes in the 2 panels 
als would be necessary to indicate that schoolmaster individuals were as specialized as lionfish.

\section{Prey fish composition}

Over 6 survey dates, 66 lionfish were sighted within the nine $3.14 \mathrm{~m}^{2}$ survey areas. Although lionfish were not tagged to assess whether the same individuals were present in each survey, repeated sightings (including lionfish individuals within the same $0.2 \mathrm{~m}$ radius on all survey dates) suggest a relatively high degree of site fidelity over this $3 \mathrm{wk}$ study period (also see Jud \& Layman in press). Prey assemblages differed significantly among patch habitats (ANOSIM: global $R=0.47$, p < 0.001; Fig. 5). Some of the patches tended to have distinct fish assemblages across study dates, which drove this significant result. For example, Site $\mathrm{H}$ was distinct because juvenile grunts $(<8 \mathrm{~cm})$ were common. Grunts were present at this site in each of the 6 surveys, with as many as 100 individuals within the survey area on a sampling date. Grunts were only sighted in 3 of the other 48 surveys. Dusky damselfish Stegastes adustus were always sighted at Site $\mathrm{C}$, thereby rendering this patch-habitat fish assemblage distinct. Other sites had more overlapping species composition across survey dates; e.g. Sites A, $\mathrm{B}$, and D were characterized by similar assemblages, with bluehead wrasse, beaugregory damselfish, and sergeant major damselfish Abudefduf saxatilis as the most common species.

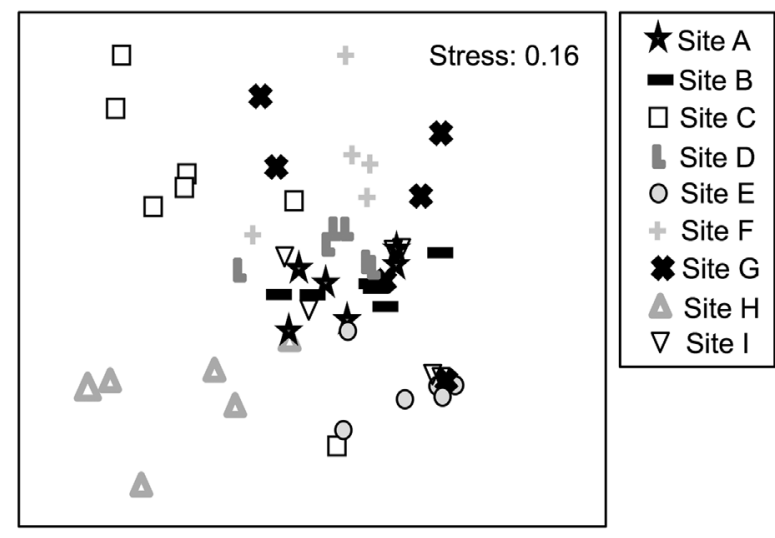

Fig. 5. Nonmetric multi-dimensional scaling plot of fish communities surveyed on the 9 patch habitats across 6 survey dates over the 3 wk study period. Each point represents a single survey $(\mathrm{n}=54)$, and each symbol represents a specific site. Surveys with more similar species composition are closer together in the 2-dimensional plot. Some symbols that were in the exact same spot (i.e. identical species compositions) are offset slightly for visualization purposes

\section{DISCUSSION}

Lionfish are widely regarded as generalist predators with an extremely broad dietary niche (Morris \& Akins 2009, Côté \& Maljkovic 2010, Jud et al. 2011, Muñoz et al. 2011), perhaps one of the reasons they have been such successful invaders in the Caribbean region. Using a series of complementary trophic analyses, we provide additional insight into the nature of this dietary generality from a back reef system in the Bahamas. We structure this section around 4 themes that emerged from our analyses: (1) a broad population-level niche of lionfish, (2) the fact that this broad population dietary niche may, under certain circumstances, consist of individuals with relatively specialized diets, (3) such specialization is dependent on variation in prey assemblages among patch habitats in relation to the scale of individual lionfish movements, and (4) the importance of using direct diet data information in conjunction with stable isotope data to characterize the trophic ecology of apparently generalist species.

Consistent with previous studies that have characterized lionfish trophic ecology (Morris \& Akins 2009, Côté \& Maljkovic 2010, Jud et al. 2011, Muñoz et al. 2011), our data suggest that lionfish, at the population level, have a broad dietary niche. In 99 lionfish individuals that had identifiable stomach contents, we identified 22 taxa. Small fishes were most common, although a diverse suite of crustacean taxa also were identified. In general, isotope values of these prey items suggest that lionfish are feeding across multiple trophic levels (demonstrated by the range in prey $\delta^{15} \mathrm{~N}$ ), and on prey that rely on diverse basal resource pools and occupy various functional roles (as inferred from the variation in prey $\delta^{13} \mathrm{C}$ ). Yet, through the application of a recently developed model that integrates diet and stable isotope information (Araújo et al. 2007, 2011), our data also suggest a high degree of specialization at the individual level in the local lionfish population (among the highest $15 \%$ of individual specialization values reported for any fish species; Fig. 4). The only way that the empirical lionfish $\delta^{13} \mathrm{C}$ variance (which is a direct function of their prey items and the isotope signatures of those prey) could be manifest is if individual lionfish were specializing on prey with distinct isotopic signatures. That is, variance in lionfish $\delta^{13} \mathrm{C}$ values was relatively high relative to variance in $\delta^{13} \mathrm{C}$ of their prey.

The observation that individuals may be localized specialists is likely rooted in the interaction between lionfish foraging behavior (e.g. prey selection and 
foraging range) and the scales at which prey assemblages may vary. Although lionfish are capable of moving tens of meters in foraging bouts (Green et al. 2011), most individuals appear to have relatively high short-term site fidelity (Côté \& Maljkovic 2010, Jud \& Layman in press) and may consume primarily those prey located in close proximity to the structurally complex habitats they inhabit (Côté \& Maljkovic 2010, Jud \& Layman in press). Our data parallels the observation of Muñoz et al. (2011), i.e. that lionfish prey choice tracks availability of local prey species. Although patch reef fish assemblages can vary through time (Sale \& Douglas 1984, Syms \& Jones 2000), distinct patch reef fish communities (characterized by a distinct $\delta^{13} \mathrm{C}$ signature) may persist over sufficient time scales (i.e. weeks to months) for this signature to be reflected in a lionfish individual. Our findings suggest that the degree of local specialization in individual lionfish diets may be a function of both the temporal variability in potential prey fish assemblages and the spatial scale over which lionfish feed. The relative degree of individual-level specificity likely varies substantially among study sites and environmental contexts, and this fact should be taken into consideration when extrapolating the effects that lionfish may have on local prey communities.

The comparison with schoolmaster snapper is informative here. Schoolmaster snapper individuals forage over a scale of tens to hundreds of meters over a span of hours in these Bahamian ecosystems (Hammerschlag-Peyer \& Layman 2010), thus allowing for prey selection across multiple habitat types (Hitt et al. 2011). Foraging at this scale would allow individuals to sample from a larger potential prey pool, not just the organisms that inhabit a resident patch. Further, prey recognition of predators may relate to the observed patterns. Recent experimental work suggests that native fishes recognize snapper, but not lionfish, as predators (A. Anton unpubl. data). This fact may serve to increase prey capture efficiency by lionfish, and may help explain why lionfish can rely primarily on those fishes that are found near their resident habitat patch. Conversely, schoolmaster prey have co-evolved with the native predators, and may have specific responses that reduce efficiency of schoolmaster prey recognition and capture. Reduced predation efficiency at a local scale may relate to apparently larger daily foraging ranges of schoolmaster (relative to lionfish).

These findings have implications for the examination and interpretation of the degree of individual specialization across populations. Inquiry regarding individual specialization has grown rapidly over the past decade (Araújo et al. 2011), and interpretations of results from related models (e.g. from Semmens et al. 2009, Araújo et al. 2011) must be made with a keen eye toward basic natural history of the study system and organisms. The present case is an example of how understanding the spatial scales and grains at which predator and prey are distributed affects interpretation of dietary patterns (Rose \& Leggett 1990, Ives et al. 1993). Although lionfish are capable of consuming a wide range of prey, a case of apparent individual-level specialization may be driven by the grain at which prey are distributed across the seascape. These data emphasize how behavior, of both predators and prey, has an important influence on the incidence and strength of individual specialization within populations (Bolnick et al. 2007).

Some caveats are important to note with respect to these data and analyses. First, a core criterion for applying specialization models is that the prey collected for isotope analysis must, both spatially and temporally, be reflective of those prey on which the consumer individuals actually fed (Araújo et al. 2007, 2011, Layman et al. 2011). Yet because isotope values of prey can vary over relatively small spatial scales and short time frames (Post 2002), and the exact area over which consumer individuals feed is often unknown, meeting this criterion is often difficult in practice. As the prey collected for the isotope analysis diverges from the prey assemblages that the consumers actually utilize, model outputs become less representative of the actual strength of individual specialization in a consumer population. For example, prey fish assemblage composition was evaluated during daylight hours in the present study, but lionfish may expand their foraging range during crepuscular or nocturnal time periods (Green et al. 2011). As such, lionfish may be foraging over larger areas, or on different prey assemblages due to diurnal or nocturnal fish assemblage differences, than is suggested herein. Since specialization in diet is a function of the available prey pool, temporal variation in prey communities may further complicate linking diet data, isotope data, and feeding behavior of lionfish.

In addition, as is always the case with stable isotope applications, numerous factors affect $\delta^{15} \mathrm{~N}$ and $\delta^{13} \mathrm{C}$ values, so that these data provide for only indirect inference into aspects of trophic ecology. As such, conclusions based solely on isotope data must be qualified and interpreted accordingly (Martinez del Rio et al. 2009, Layman et al. 2011). These considerations emphasize the critical role of understanding the natural history of focal organisms, especially 
when using isotope data as input to analytical models of trophic relationships (Layman et al. 2011).

Our findings suggest important future directions in the study of the lionfish invasion. (1) Why or how do lionfish choose particular habitat types? For example, why are they found exclusively in association with human-made structures in some systems (Jud et al. 2011), but are abundant in natural habitat types in others (Côté \& Maljkovic 2010)? (2) Is the density of prey a determinant of lionfish habitat selection, and will local prey depletion lead to movement away from local habitat patches according to the basic tenets of optimal foraging theory (Pyke et al. 1977)? (3) Stable isotopes and diet data provide information regarding the flow of energy (or nutrients) through food webs. They do not provide definitive information as to the functional relationships among organisms (e.g. whether a predator actually controls the abundance of a given prey), information that typically necessitates controlled experiments (Paine 1980, Polis \& Winemiller 1996, Layman et al. 2011). Initial experiments suggest that lionfish may have important impacts on prey populations (Albins \& Hixon 2008), and such experiments will continue to be an essential component of understanding the long-term changes that lionfish might induce in the invaded range. Our data suggest that lionfish prey selection, and thus their functional role, may vary substantially among patches or habitats where they reside. As such, the functional role of lionfish needs to be evaluated independently across ecosystems and ecological contexts.

Acknowledgements. Support for this study was provided by the NSF (OCE no. 0746164 and OCE no. 0940019). K. Rennirt provided field assistance throughout the project. M. Araújo provided comments on the data analysis and manuscript preparation. Friends of the Environment, Abaco, The Bahamas, served as our local educational and outreach partner.

\section{LITERATURE CITED}

Adams AJ, Dahlgren CP, Kellison GT, Kendall MS and others (2006) Nursery function of tropical back-reef systems. Mar Ecol Prog Ser 318:287-301

Albins MA, Hixon MA (2008) Invasive Indo-Pacific lionfish Pterois volitans reduce recruitment of Atlantic coral-reef fishes. Mar Ecol Prog Ser 367:233-238

Araújo MS, Bolnick DI, Machado G, Giaretta AA, dos Reis SF (2007) Using delta C-13 stable isotopes to quantify individual-level diet variation. Oecologia 152:643-654

> Araújo MS, Bolnick DI, Layman CA (2011) The ecological causes of individual specialization. Ecol Lett 14:948-958

> Barbour AB, Montgomery ML, Adamson AA, Diaz-Ferguson E, Silliman BR (2010) Mangrove use by the invasive lionfish Pterois volitans. Mar Ecol Prog Ser 401:291-294
Bertness MD (1984) Habitat and community modification by an introduced herbivorous snail. Ecology 65:370-381

Bolnick DI, Yang LH, Fordyce JA, Davis JM, Svanback R (2002) Measuring individual-level resource specialization. Ecology 83:2936-2941

Bolnick DI, Svanbäck R, Fordyce JA, Yang LH, Davis JM, Hulsey CD, Forister ML (2003) The ecology of individuals: incidence and implications of individual specialization. Am Nat 161:1-28

> Bolnick DI, Svanbäck R, Araujo MS, Persson L (2007) Comparative support for the niche variation hypothesis that more generalized populations also are more heterogeneous. Proc Natl Acad Sci USA 104:10075-10079

Bolnick DI, Amarasekare P, Araujo MS, Burger R and others (2011) Why intraspecific trait variation matters in community ecology. Trends Ecol Evol 26:183-192

Bray JR, Curtis JC (1957) An ordination of the upland forest communities of southern Wisconsin. Ecol Monogr 27: 325-349

> Byrnes JE, Reynolds PL, Stachowicz JJ (2007) Invasions and extinctions reshape coastal marine food webs. PLoS ONE 2:e295

> Carlton JT (1989) Man's role in changing the face of the ocean: biological invasions and implications for conservation of near-shore environments. Conserv Biol 3:265-273

Clavel J, Julliard R, Devictor V (2011) Worldwide decline of specialist species: toward a global functional homogenization? Front Ecol Environ 9:222-228

Côté IM, Maljkovic A (2010) Predation rates of Indo-Pacific lionfish on Bahamian coral reefs. Mar Ecol Prog Ser 404: 219-225

> DeNiro MJ, Epstein S (1981) Influence of diet on the distribution of nitrogen isotopes in animals. Geochim Cosmochim Acta 45:341-351

Green SJ, Akins JL, Côté IM (2011) Foraging behaviour and prey consumption in the Indo-Pacific lionfish on Bahamian coral reefs. Mar Ecol Prog Ser 433:159-167

> Hammerschlag-Peyer CM, Layman CA (2010) Intrapopulation variation in habitat use by two abundant coastal fish species. Mar Ecol Prog Ser 415:211-220

Hitt S, Pittman SJ, Nemeth RS (2011) Diel movements of fishes linked to benthic seascape structure in a Caribbean coral reef ecosystem. Mar Ecol Prog Ser 427: 275-291

- Ives AR, Kareiva P, Perry R (1993) Response of a predator to variation in prey density at 3 hierarchical scales: lady beetles feeding on aphids. Ecology 74:1929-1938

> Jackson JBC, Kirby MX, Berger WH, Bjorndal KA and others (2001) Historical overfishing and the recent collapse of coastal ecosystems. Science 293:629-637

> Jackson AL, Inger R, Parnell A, Bearhop S (2011) Comparing isotopic niche widths among and within communities: SIBER-Stable Isotope Bayesian Ellipses in R. J Anim Ecol 80:595-602

Jud ZR, Layman CA (in press) Site fidelity and movement patterns in the invasive lionfish, Pterois spp. J Exp Mar Biol Ecol

Jud ZR, Layman CA, Lee JA, Arrington DA (2011) Recent invasion of a Florida (USA) estuarine system by lionfish Pterois volitans /P. miles. Aquat Biol 13:21-26

> Kolar CS, Lodge DM (2001) Progress in invasion biology: predicting invaders. Trends Ecol Evol 16:199-204

> Layman CA, Post DM (2008) Can stable isotope ratios provide for community-wide measures of trophic structure? Reply. Ecology 89:2358-2359 
Layman CA, Arrington DA, Montaña CG, Post DM (2007a) Can stable isotope ratios provide quantitative measures of trophic diversity within food webs? Ecology 88:42-48

Layman CA, Quattrochi JP, Peyer CM, Allgeier JE (2007b) Niche width collapse in a resilient top predator following ecosystem fragmentation. Ecol Lett 10:937-944

Layman CA, Araújo MS, Boucek R, Hammerschlag-Peyer CM and others (2011) Applying stable isotopes to examine food-web structure: an overview of analytical tools. Biol Rev. doi:10.1111/j.1469-185X.2011.00208.x

Lotze HK, Lenihan HS, Bourque BJ, Bradbury RH and others (2006) Depletion, degradation, and recovery potential of estuaries and coastal seas. Science 312:1806-1809

Loxdale HD, Lushai G, Harvey JA (2011) The evolutionary improbability of 'generalism' in nature, with special reference to insects. Biol J Linn Soc Lond 103:1-18

Mack RN, Simberloff D, Lonsdale WM, Evans H, Clout M, Bazzaz FA (2000) Biotic invasions: causes, epidemiology, global consequences, and control. Ecol Appl 10:689-710

Martinez del Rio C, Wolf N, Carleton SA, Gannes LZ (2009) Isotopic ecology ten years after a call for more laboratory experiments. Biol Rev Camb Philos Soc 84:91-111

McCutchan JH, Lewis WM, Kendall C, McGrath CC (2003) Variation in trophic shift for stable isotope ratios of carbon, nitrogen, and sulfur. Oikos 102:378-390

McKinney ML, Lockwood JL (1999) Biotic homogenization: a few winners replacing many losers in the next mass extinction. Trends Ecol Evol 14:450-453

Morris JA Jr, Akins JL (2009) Feeding ecology of invasive lionfish (Pterois volitans) in the Bahamian archipelago. Environ Biol Fishes 86:389-398

Mumby PJ, Harborne AR, Brumbaugh DR (2011) Grouper as a natural biocontrol of invasive lionfish. PLoS ONE 6: e21510

Muñoz RC, Currin CA, Whitfield PE (2011) Diet of invasive lionfish on hard bottom reefs of the Southeast USA: insights from stomach contents and stable isotopes. Mar Ecol Prog Ser 432:181-193

Olden JD, Poff NL, Douglas MR, Douglas ME, Fausch KD (2004) Ecological and evolutionary consequences of biotic homogenization. Trends Ecol Evol 19:18-24

Paine RT (1980) Food webs: linkage, interaction strength, and community infrastructure. J Anim Ecol 49:667-685

Parnell AC, Inger R, Bearhop S, Jackson AL (2010) Source partitioning using stable isotopes: coping with too much variation. PLoS ONE 5:e9672

Peterson BJ, Fry B (1987) Stable isotopes in ecosystem studies. Annu Rev Ecol Syst 18:293-320

Polis GA, Winemiller KO (eds) (1996) Food webs. Integration of patterns and processes. Chapman \& Hall, New York, NY

Post DM (2002) Using stable isotopes to estimate trophic position: models, methods, and assumptions. Ecology 83: 703-718

Editorial responsibility: Ivan Nagelkerken, Nijmegen, Netherlands
Post DM, Layman CA, Arrington DA, Takimoto G, Montaña CG, Quattrochi J (2007) Getting to the fat of the matter: models, methods and assumptions for dealing with lipids in stable isotope analyses. Oecologia 152:179-189

> Pyke GH, Pulliam HR, Charnov EL (1977) Optimal foraging: a selective review of theory and tests. Q Rev Biol 52: 137-154

Qian H, Ricklefs RE (2006) The role of exotic species in homogenizing the North American flora. Ecol Lett 9: 1293-1298

Rose GA, Leggett WC (1990) The importance of scale to predator-prey spatial correlations: an example of Atlantic fishes. Ecology 71:33-43

Ruiz GM, Fofonoff P, Hines AH, Grosholz ED (1999) Nonindigenous species as stressors in estuarine and marine communities: assessing invasion impacts and interactions. Limnol Oceanogr 44:950-972

Sale PF, Douglas WA (1984) Temporal variability in the community structure of fish on coral patch reefs and the relation of community structure to reef structure. Ecology 65: 409-422

> Schoener T (1968) The Anolis lizards of Bimini: resource partitioning in a complex fauna. Ecology 49:704-726

Schofield PJ (2009) Geographic extent and chronology on the invasion of non-native lionfish (Pterois volitans [Linnaeus 1758] and P. miles [Bennett 1828]) in the Western North Atlantic and Caribbean Sea. Aquat Invasions 4: 473-479

Semmens BX, Ward EJ, Moore JW, Darimont CT (2009) Quantifying inter- and intra-population niche variability using hierarchical Bayesian stable isotope mixing models. PLoS ONE 4:e6187

Sutherland WJ, Clout M, Côté IM, Daszak P and others (2010) A horizon scan of global conservation issues for 2010. Trends Ecol Evol 25:1-7

Syms C, Jones GP (2000) Disturbance, habitat structure, and the dynamics of a coral-reef fish community. Ecology 81: 2714-2729

Turner TF, Collyer ML, Krabbenhoft TJ (2010) A general hypothesis-testing framework for stable isotope ratios in ecological studies. Ecology 91:2227-2233

Valentine-Rose L, Layman CA, Arrington DA, Rypel AL (2007) Habitat fragmentation affects fish secondary production in Bahamian tidal creeks. Bull Mar Sci 80: 863-878

Whitfield PE, Gardner T, Vives SP, Gilligan MR, Courtenay WR Jr, Ray GC, Hare JA (2002) Biological invasion of the Indo-Pacific lionfish Pterois volitans along the Atlantic coast of North America. Mar Ecol Prog Ser 235: 289-297

> Yeager LA, Allgeier JA, Layman CA (2011) Experimental test of the importance of landscape and patch scale variables in predicting fish community assembly. Oecologia 167:157-168

Submitted: July 4, 2011; Accepted: November 19, 2011 Proofs received from author(s): February 12, 2012 